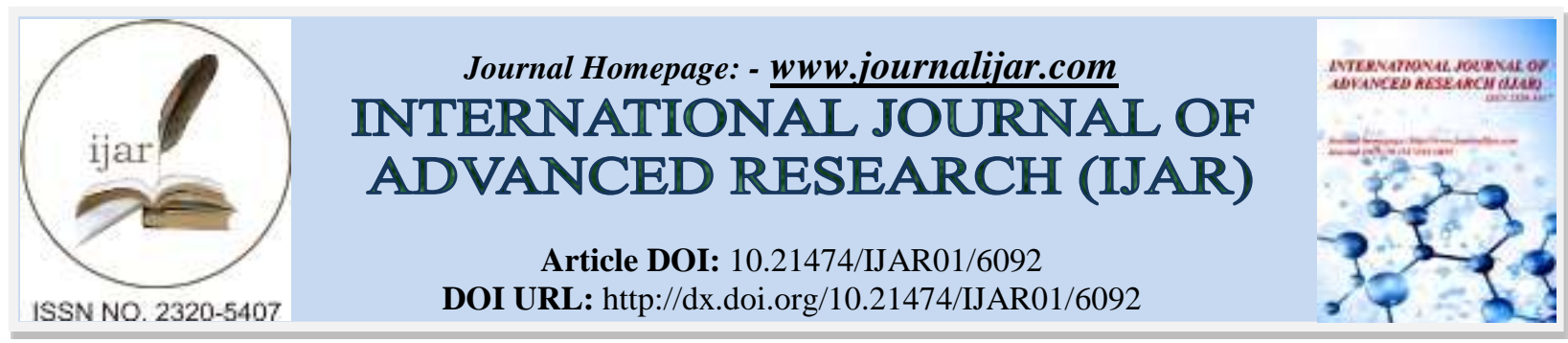

RESEARCH ARTICLE

\title{
AN INTERESTING CASE OF FAMILIAL HOMOZYGOUS HYPERCHOLESTEROLEMIA, SFH RIYADH KSA.
}

\section{Amjaad AlMarjan and Fawwaz AlMutairi.}

\section{Manuscript Info}

[.........................

Manuscript History

Received: 18 October 2017

Final Accepted: 18 November 2017

Published: December 2017

\section{Abstract}

Familial hypercholesterolemia is an inherited condition that cause high level of LDL and cholesterol levels beginning birth. Familial hypercholesterolemia is run in families in an autosomal manner. In autosomal dominant inherited conditions, a parent who carries an altered gene that cause the condition has 1 to 2 (50 percent ) chance to pass on that altered gene to each of his or her children. There are two types of FH heterozygous and homozygous. Heterozygous occurs when the FH mutation is inherited from one parent, while homozygous occurs when FH inherited from both parents. It's much rarer . People with this condition have very high LDL cholesterol levels, many need bypass surgery before adulthood .Without treatment, these people rarely into their 20 s.

Copy Right, IJAR, 2017,. All rights reserved.

\section{Introduction:-}

Familial hypercholesterolemia is best defined as an entity in clinical practice that is recognizable from patient's family history as well as personal history and clinical presentation with physical examination. Sub clinical atherosclerosis is evident in young patients with FH when sought with medical imaging techniques . Atherosclerosis is imperfectly understood, but is clearly a multifactorial disease in which especially in FH, LDL hypercholesterolemia plays a strong role. In FH atherosclerosis is more severe and results in clinical complications earlier .

\section{Case Report:-}

This is a 26 years old, unmarried female presented to ED because of left shoulder pain for 8 days . Kholoud is a known case Familial hypercholesterolemia ,HTN , IDA, Multiple sclerosis. Came complaining of contentious left shoulder pain that getting worse with time, radiated to the back towards vertebral column. Pain is increased gradually along 8 days . aggravated with laying supine on bed, affects her sleeping quality and awaking her many times, she sleep over two pillows to feel better, It's also become worse with exertion or when she climbs the stairs Severity is 4 out of 10 as the patient mentioned. It's associated with diaphoresis and nausea . No numbness, no recent trauma or syncope attack. No changes over appetite or weight .

Review of systems :

CNS: Multiple sclerosis

CVS: CAD

Respiratory : Unremarkable

GIT: Unremarkable

MSK: Xnthoma bilateral knee joints, bilateral elbow , and bilateral hand and foot . 
History:

MEDICAL Hx : CAD , HTN, Iron deficiency anemia , Multiple sclerosis diagnose 2013

Surgical Hx: Appendectomy

Hospital admission : 2014 for PCI , No ICU admission

Medications : Aspirin $81 \mathrm{mg}$, Atorvastatin

Blood transfusion : 2 backed RBCs

Family Hx: +ve parents consanguinity .

Mother : DM type2, on oral glucose lowering agents

Father : Familial hypercholesterolemia, HTN underwent CABG

Siblings : Sudden death occurred for one of his brother at age of 12 years old, other siblings found to have mild elevation in blood cholesterol .

General examination of the patient :

Patient is alert, conscious, oriented to the time and place

Looks tired and pale, complaining of pain in her left shoulder

Height $154 \mathrm{~cm}$, weight 38

BP: 133/54, HR: 83 bp

RR: 17 bp

O2: 100 room air

Chest : clear , Equal bilateral air entry

CVS: S1 , S2 +Ejection systolic murmur at aortic area .

Abdomen : soft and lax non tender

CNS : Intact reflexes, normal motor and sensory .

SKIN: Revealed extensive and multiple tendinous and tuberous xanthoma of varying sizes ranging from 1 to $12 \mathrm{~cm}$, distributed mainly over knees, elbows, hands and feet. Yellowish plaque like appearance along the dorsum of hands .Also, dorsum of hands showed characteristic involvement of interdigital spaces and knuckles showing the pathogenomic intertriginous xanthomas.

Eyes: Xanthelesma palpebrarum around eyes lids, arcus juvnalis.

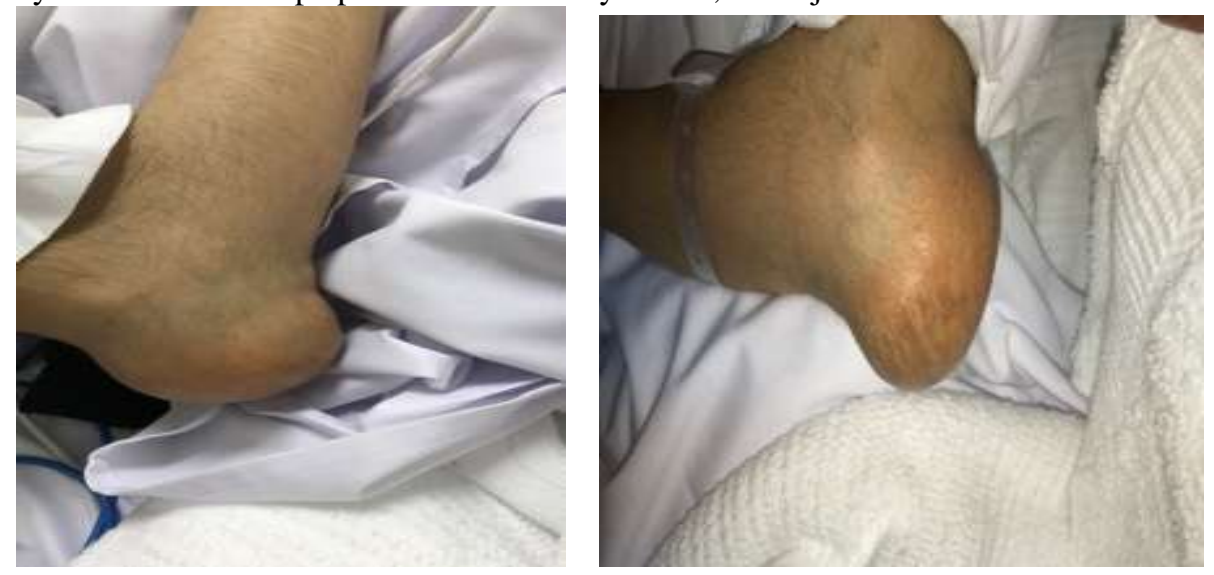



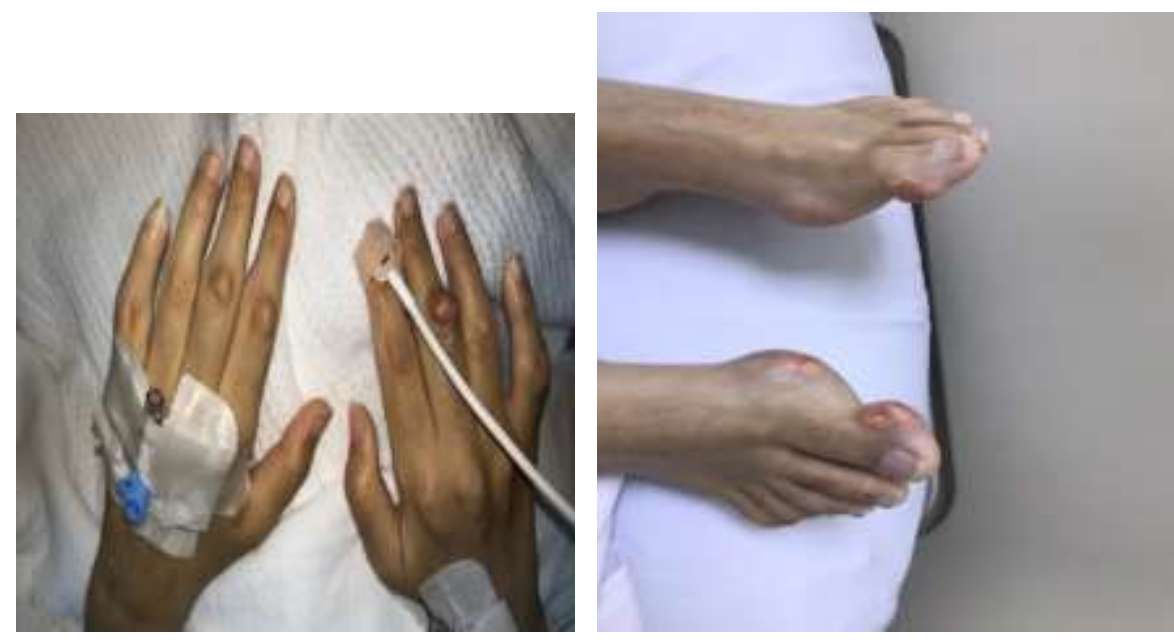

Laboratory investigations:-

Complete blood count:- $\quad$ WBC 7.92

RBC 4.02

$\mathrm{Hb} 8.7$

HCT 0.294

MCH 21.6

MCHC 296.0

RDW 16.6

PLATELETS 258

Liver function test:- $\quad$ ALT 17

AST 18

BILIRUBIN 3.7

GAMMA GT 13

PROTEIN 74

ALBUMIN 40

GLOBULINS 34.0

Electrolytes , UR, CR:- $\quad$ Sodium 135

Potassium 3.8

Chloride 101

Urea 6.4

Creatinine 45

Cardiac profile:- $\quad$ Troponin 0.237

Thyroid function test: TSH 0.01

FT3 6.4

FT4 31.5

Coagulation profile :- $\quad$ PT 12.4

INR 1.07

APTT 42.7

Lipid profile:- $\quad$ Cholesterol 14.78

TRIGS 1.81

LDL 13.32 VERY HIGH, HDL : 0.64 LOW

Electrocardiogram showed:-

Diffuse ST depression in Anterolateal leads involving inferior. Sinus tachycardia. 


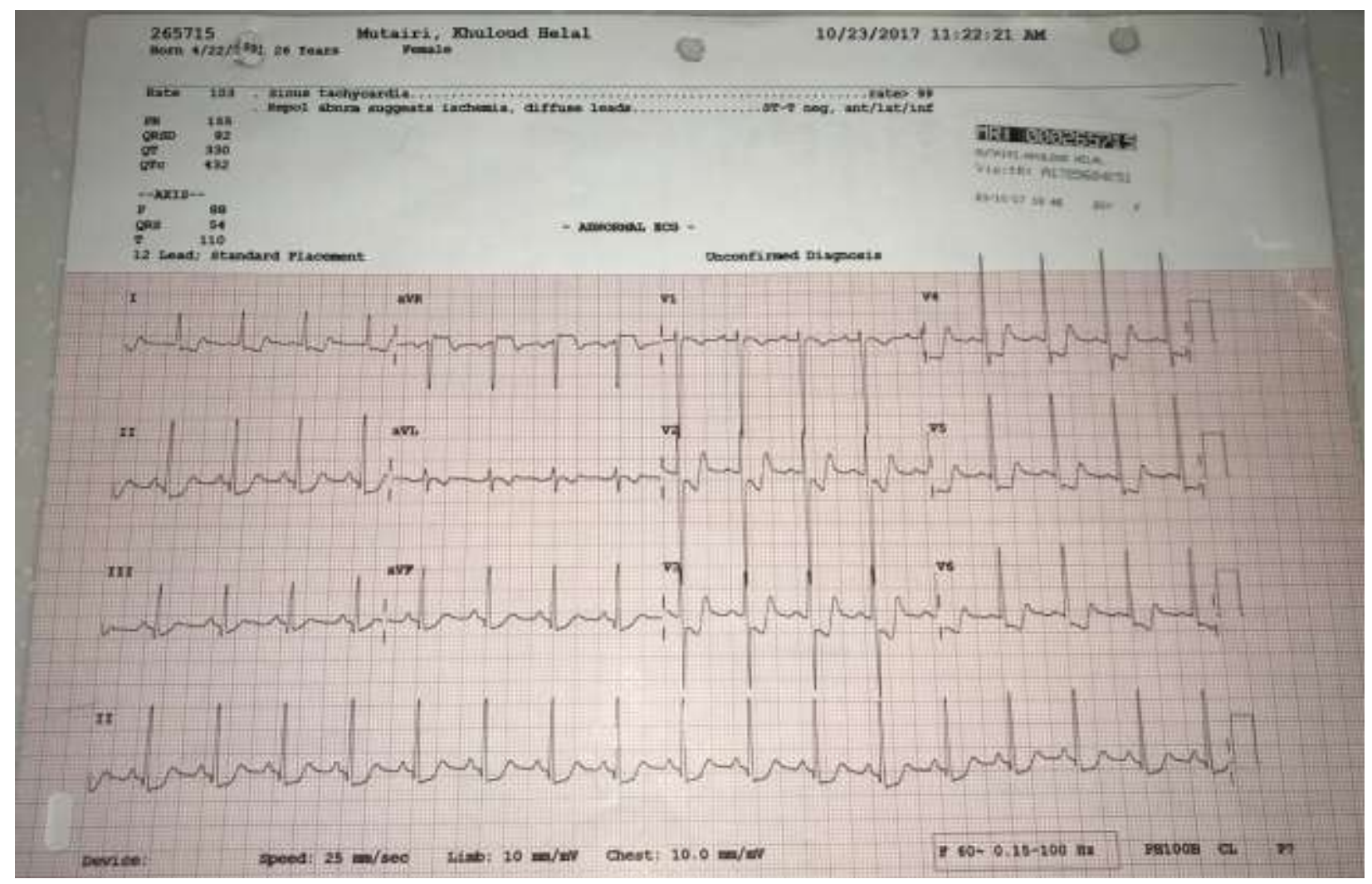

\section{Discussion:-}

With the available laboratory data and clinical findings, it was established that the patient had Homozygous FH . Extensive left main stenosis Ostia $70 \%$, distal 90\% . LCX : Ostial $90 \%$ and LAD: Ostial : 90\% stenosis , proximal and mid diffuse $80 \%$ stenosis . RCA : Ostial 90\% stenosis . ECG Showed diffuse anterolateal ST depression in all leads involving inferior leads with high troponin. So , the plan for the patient was urgent referral to military hospital in Riyadh for LDL pharesis and Coronary artery bypass surgery .

\section{Conclusion:-}

Homozygous familial hypercholesterolemia inherits two mutal allels of the FH gene and consequently has six to eight folds elevation in plasma LDL cholesterol levels. It is a rare disease in which approximately 1 in 1 million persons in the general population are affected. These patients often present with the development of xenthomatosis before the first decade of life. Homozygous FH patients also develop symptomatic CAD in early childhood . Untreated negative receptors patients rarely survived beyond the second decade. Early interventions with anti cholesterol medications and highly restricted cholesterol diet is very important to protect from the harmful morbidity and early mortality among those with FH . As in our case we reported this lady in her early twenties with severely affected $\mathrm{CAD}$ and the need for CABG .

\section{Reference:-}

1. Mose J ., Omolola B ., (2017). Familial Hypercholesterolemia. Med escape cursoenarm.net/UPTODATE/contents/mobipreview.htm?31/18/32046

2. David M .,( 2005) . Familial Hypercholesterolemia . The Clinical Biochemist Reviews. ISSN 0159 - 8090 https://www.ncbi.nlm.nih.gov/pmc/articles/PMC1853359/

3. Ose L. Muller-Harbitz disease--familial hypercholesterolemia. Tidsskr Nor Laegeforen. 2002;122:924-5. [PubMed]

4. Myant NB. Familial defective apolipoprotein B-100: a review, including some comparisons with familial hypercholesterolemia. Atherosclerosis. 1993;104:1-18. [PubMed]

5. Shubha J ., S.Meera ., Sumangala K ., N.Sreenivasa . Intersting case of familial homozygous hypercholesterolemia abrief review(2011). doi: 10.1007/s12291-011-0165-8 https://www.ncbi.nlm.nih.gov/pmc/articles/PMC4577508/. 